\title{
Heart inflammation risk after COVID-19 vaccine
}

\author{
Lukasz Szarpak ${ }^{1,2,3} \odot$, Michal Pruc ${ }^{3} \odot$, Mariusz Koda $^{2} \odot$, Francesco Chirico ${ }^{4,5} \odot$ \\ ${ }^{1}$ Institute of Research Outcomes, Maria Sklodowska-Curie Medical Academy, Warsaw, Poland \\ ${ }^{2}$ Research Unit, Maria Sklodowska-Curie Bialystok Oncology Center, Bialystok, Poland \\ ${ }^{3}$ Research Unit, Polish Society of Disaster Medicine, Warsaw, Poland \\ ${ }^{4}$ Post-graduate School of Occupational Health, Università Cattolica del Sacro Cuore, Rome, Italy \\ ${ }^{5}$ Health Service Department, Italian State Police, Milan, Italy
}

The severe acute respiratory syndrome coronavirus 2 (SARS-CoV-2) has caused a severe threat to the healthcare system and medical personnel since the beginning of the pandemic [1]. The vaccination program against coronavirus disease 2019 (COVID-19) has been in Europe for a long period. After taking the preparation, some patients have unfavorable post-vaccination responses. The majority of them are minor, but they can be, in individual cases, significant or severe. One of the primary reasons why people do not take COVID-19 vaccinations is because they are afraid of the negative effects. Myocarditis and SARS-CoV-2 infection are linked in a major way [2]. Myocarditis is an uncommon side effect of mRNA immunization, especially in younger and adult males, and occurs most usually after the second dosage with a 7-day gap. Myocarditis accounted for $0.4 \%$ of all vaccine-related adverse events, according to an observational analysis of 151.1 million persons who had been vaccinated. The number of instances of post-vaccination myocarditis was 0.95 per 100,000 , and 1.05 per 100,000 in younger men under the age of 18 , whereas in the whole population it was expected to be 2.12 per 100,000 [3]. Two Israeli studies estimate the risk of myocarditis after receiving the Pfizer-BioNTech injection, with one estimating a two in 100,000 probability of acquiring the illness. A total of 136 persons suffered myocarditis after receiving the Pfizer-BioNTech COVID-19 vaccination in one trial of more than 5,1 million participants. Within 1 month of receiving a Pfizer injection, 136 incidences of myocarditis were detected, according to the study. Ninety-five percent of the cases were mild, but one individual died. After getting their second dosage of the Pfizer-BioNTech vaccine, up to 4 in 100,000 males experienced myocarditis, although the prevalence for women was less than 1 in 100,000. In general, fully vaccinated people were nearly twice as likely as unvaccinated people to be diagnosed with myocarditis after their second dose, however, young males aged 16-19 had a 15 in 100,000 risk of getting myocarditis. The great majority of these incidents were mild and addressed quickly. Myocarditis was also more likely to develop after the second vaccination dosage than after the first, according to the researchers [4]. Only 54 incidences of myocarditis were found in the other trial, which included more than 2.5 million participants who got the vaccine. Also, they discovered that 2 out of every 100,000 persons who had at least one Pfizer injection suffered myocarditis, with the rate rising to almost 11 out of 100,000 in males aged 16-29. Overall, mild symptoms accounted for $76 \%$ of the cases, whereas moderate symptoms accounted for $22 \%$ [5]. According to the $\mathrm{CDC}$, the risk of myocarditis in hospitalized patients infected with COVID-19 is 15.7 times higher than in individuals who have not been exposed to the virus [6]. Furthermore, men are more likely than women to acquire myocarditis as a result of SARS-CoV-2 infection, with the risk being highest in children under the age of 16 and in the elderly over the age of 50. In adults 16 and older, the danger of getting myocarditis is outweighed by the COVID-19 vaccination. Infection

Address for correspondence: Lukasz Szarpak, Assoc. Prof. PhD, DPH, DBA, MBA, Institute of Research Outcomes, Maria Sklodowska-Curie Medical Academy, Al. Solidarności 12, 03-411 Warszawa, Poland, e-mail: lukasz.szarpak@gmail.com Received: 28.11.2021 Accepted: 4.12.2021

Early publication date: 7.12 .2021

This article is available in open access under Creative Common Attribution-Non-Commercial-No Derivatives 4.0 International (CC BY-NC-ND 4.0) license, allowing to download articles and share them with others as long as they credit the authors and the publisher, but without permission to change them in any way or use them commercially. 
with SARS-CoV-2 was found to be 18 times more likely to cause myocarditis in this age range in previous investigations, a substantially larger risk than that reported after vaccination [7]. We should also be aware of the consequences of LONG-COVID-19 illness, including the possibility of myocarditis [8]. Data from $1 / 5$ of the United States population was also evaluated, revealing that in the first 12 months of the pandemic, men aged 12 to 17 years old were most likely to have myocarditis within 3 months after COVID-19 infection, with an incidence of around 450 per million infections [9]. This is especially essential since immunizations also protect against the LONG-COVID-19 syndrome, COVID-19-induced myocarditis, and consequences such acute renal failure, arrhythmia, and thrombosis. The risk of heart inflammation from the COVID-19 vaccine is extremely low, and given the benefits of vaccination, such as a significantly lower risk of hospitalization and severe course, as well as a significantly higher risk of developing myocarditis during the disease or during the course of LONG-COVID-19, this should not be a deterrent to vaccinate or cause concern among the public and physicians. Failure to vaccinate will result in more damage and a higher risk of myocarditis in the case of infection, which is extremely likely given the current SARS-CoV-2 viral incidence. We should not be scared of this vaccination since it is the only effective form of protection against COVID-19 presently available, especially because it minimizes the chance of the virus mutating and evading immune control [10]. Given the present status of the pandemic, it appears that SARS-CoV-2 exposure is unavoidable.

\section{Acknowledgments}

The study was supported by the ERC Research Net and by the Polish Society of Disaster Medicine.

Conflict of interest: None declared

\section{References}

1. Dzieciatkowski T, Szarpak L, Filipiak KJ, et al. COVID-19 challenge for modern medicine. Cardiol J. 2020; 27(2): 175-183, doi: 10.5603/CJ.a2020.0055, indexed in Pubmed: 32286679.

2. Wańha W, Wybraniec M, Kapłon-Cieślicka A, et al. Myocardial infarction in the shadow of COVID-19. Cardiol J. 2020; 27(5): 478-480, doi: 10.5603/CJ.2020.0152, indexed in Pubmed: 33165896.

3. Urdaneta V, Esposito D, Mansi J, et al. Myocarditis after mRNA-1273 vaccination: a population-based analysis of 151 million vaccine recipients worldwide. MedRev. 2021, doi: 10.1101/2021.11.11.21265536.

4. Mevorach D, Anis E, Cedar N, et al. Myocarditis after BNT162b2 mRNA Vaccine against Covid-19 in Israel. N Engl J Med. 2021 [Epub ahead of print], doi: 10.1056/NEJMoa2109730, indexed in Pubmed: 34614328.

5. Witberg G, Barda N, Hoss S, et al. Myocarditis after Covid-19 vaccination in a large health care organization. $\mathrm{N}$ Engl J Med. 2021 [Epub ahead of print], doi: 10.1056/NEJMoa2110737, indexed in Pubmed: 34614329.

6. Boehmer TK, Kompaniyets L, Lavery AM, et al. Association between COVID-19 and myocarditis using hospital-based administrative data - united states, march 2020-january 2021. MMWR Morb Mortal Wkly Rep. 2021; 70(35): 1228-1232, doi: 10.15585/ mmwr.mm7035e5, indexed in Pubmed: 34473684.

7. Barda N, Dagan N, Ben-Shlomo Y, et al. Safety of the BNT162b2 mRNA Covid-19 Vaccine in a Nationwide Setting. N Engl J Med. 2021; 385(12): 1078-1090, doi: 10.1056/NEJMoa2110475, indexed in Pubmed: 34432976.

8. Lorente-Ros A, Monteagudo Ruiz JM, Rincón LM, et al. Myocardial injury determination improves risk stratification and predicts mortality in COVID-19 patients. Cardiol J. 2020; 27(5): 489-496, doi: 10.5603/CJ.a2020.0089, indexed in Pubmed: 32589258.

9. Singer ME, Taub IB, Kaelber DC. Risk of myocarditis from COVID-19 infection in people under age 20: a population-based analysis. medRxiv. 2021, doi: 10.1101/2021.07.23.21260998, indexed in Pubmed: 34341797.

10. Szarpak L, Savytskyi I, Pruc M, et al. Variant lambda of the severe acute respiratory syndrome coronavirus 2 virus: A serious threat or the beginning of further dangerous mutations. Cardiol J. 2021 [Epub ahead of print], doi: 10.5603/CJ.a2021.0121, indexed in Pubmed: 34642924. 